\section{Gastrointestinal Lesions in African American Patients With Iron Deficiency Anemia}

\author{
Hassan Brim¹, Anahita Shahnazi ${ }^{1}$, Mehdi Nouraie², \\ Dilhana Badurdeen ${ }^{1}$, Adeyinka O Laiyemo', Tahmineh Haidary', \\ Ali Afsari ${ }^{1}$ and Hassan Ashktorab1 \\ 1Department of Medicine and Cancer Center, Howard University College of Medicine, \\ Washington, DC, USA. ${ }^{2}$ Department of Medicine, University of Pittsburgh, PA, USA.
}

Clinical Medicine Insights: Gastroenterology Volume 11: 1-4

(c) The Author(s) 2018

Reprints and permissions:

sagepub.co.uk/journalsPermissions.nav

DOI: $10.1177 / 1179552218778627$

\begin{abstract}
BACKGROUND: Iron deficiency anemia (IDA) is a frequent disorder that is associated with many serious diseases. However, the findings of an evaluation of IDA-associated gastrointestinal disorders are lacking among African American patients.
\end{abstract}

AIM: To determine the most prevalent gastrointestinal lesions among African American patients with IDA especially in young men.

METHODS: We reviewed medical records $(n=422)$ of patients referred for evaluation of IDA from 2008 to 2012 . Iron deficiency anemia was diagnosed using clinical laboratory tests. The results of esophagogastroduodenoscopy, colonoscopy, and pathology specimens along with demographic data were abstracted and analyzed using Stata.

RESULTS: The mean age was 61.9 years, and 50.5\% were women. In total, 189 patients (45\%) had gross gastrointestinal (GI) bleeding. The most frequent diagnoses were gastritis (40\%), benign colonic lesions (13\%), esophagitis (9\%), gastric ulcer (6\%), and duodenitis (6\%). Gl bleeding was significantly more frequent in men $(P=0.001)$. Benign and malignant colonic lesions were significantly more present among older patients: $16 \%$ vs $6 \%(P=.005)$ and $5 \%$ vs $0 \%(P=.008)$, respectively. Colitis was more prevalent in younger patients ( $\leqslant 50)$ : $11 \%$ vs $2 \%$ $(P=.001)$. In patients with gross lower Gl bleeding, the top diagnoses were gastritis (25\%), benign colon tumors (10\%), and duodenitis (6\%). Colon cancer was diagnosed among 15 patients, and all these patients were older than 50 years of age.

Conclusions: Gastritis and colonic lesions are most common associated lesions with IDA among African Americans. So bidirectional endoscopy is required for unrevealing of the cause of IDA in asymptomatic patients.

KEYWORDS: Iron deficiency anemia, GI lesions, EGD and colonoscopy

RECEIVED: May 8, 2016. ACCEPTED: May 30, 2017.

TYPE: Original Research

FUNDING: The author(s) received no financial support for the research, authorship, and/or publication of this article.
DECLARATION OF CONFLICTING INTERESTS: The author(s) declared no potential conflicts of interest with respect to the research, authorship, and/or publication of this article.

CORRESPONDING AUTHOR: Hassan Ashktorab, Department of Medicine and Cancer Center, Howard University College of Medicine, 2041 Georgia Avenue, NW, Washington, DC 20060, USA. Email: hashktorab@howard.edu

\section{Background}

Iron deficiency anemia (IDA) definition is based on the lower limit of normal in adults: $13 \mathrm{~g} / \mathrm{dL}$ in men and $12 \mathrm{~g} / \mathrm{dL}$ in women according to the World Health Organization criteria. ${ }^{1}$

Iron deficiency anemia is a common disorder that is associated with many serious diseases, including malignancies particularly of the gastrointestinal (GI) tract. Occult or gross bleeding from GI lesions is a common cause of IDA in men and postmenopausal women. ${ }^{2}$

Iron deficiency anemia occurs in $2 \%$ to $5 \%$ of adult men and postmenopausal women ${ }^{3,4}$ in the developed world and is a common cause of referral to gastroenterologists. ${ }^{5-8}$ Despite invasive procedures such as bidirectional GI endoscopy, sometimes it is challenging to diagnose and find GI source of IDA. ${ }^{9}$ Endoscopy reveals a source of IDA in 30\% to 50\% of cases. Endoscopic evaluation should not be done in women without alarm signs, abdominal symptoms, age $>50$ years, and hemoglobin $(\mathrm{Hb})<9 \mathrm{~g} / \mathrm{dL}$. Conversely, these factors are strongly associated with a GI lesion. ${ }^{10,11}$
Gastrointestinal lesions are common sources of iron deficiency, and GI evaluation is obligatory in the evaluation of this disease among men and women, young and old if the cause is not readily apparent. ${ }^{12}$ However, there is lack of data on the cause of IDA among African Americans.

In this study, we evaluated GI disorders among African Americans with IDA to determine potential GI causes of iron depletion.

\section{Methods \\ Patients}

In this retrospective study, we reviewed 650 patients' medical records from 2008 to 2012, referred for evaluation of IDA that was diagnosed using clinical laboratory tests based on $\mathrm{Hb}(\mathrm{Hb}<13 \mathrm{~g} / \mathrm{dL}$ in men and $\mathrm{Hb}<12 \mathrm{~g} / \mathrm{dL}$ in women), ferritin, and iron saturation in a single center. Iron deficiency anemia definition for our patients was based on ferritin 
level $<45 \mathrm{ng} / \mathrm{mL}$. Patients with ferritin level 46 to 99 , total iron-binding capacity level $>450 \mu \mathrm{g} / \mathrm{dL}$, and transferrin saturation $<20 \%$ were considered to have IDA.

Based on International Classification of Diseases, Ninth Revision (ICD-9) code, we selected patients. Out of 650 patients who underwent endoscopy, 422 (65\%) patients had GI pathology and 228 (35\%) patients had a normal GI endoscopy. We focused on patients with GI pathology and evaluated them. Gastrointestinal bleeding definition was based on ICD-9 as well. In total, $45 \%$ of patients had gross GI bleeding and $55 \%$ of them without gross GI bleeding had occult GI bleeding and or without any occult bleeding. Gastrointestinal bleeding was defined as hematochezia, melena, and hematemesis. Microcytic hypochromic anemia secondary to thalassemia, sideroblastic anemia, and lead poisoning was excluded. Gastrointestinal lesions were diagnosed in a single center of the hospital based on esophagogastroduodenoscopy (EGD), colonoscopy, and pathology data. We evaluated GI lesions that were diagnosed by demographic characteristics of the patients.

Patients who had active symptoms were 220 (52\%) and without active symptoms were 202 (48\%). Patient with active GI symptoms had symptoms such as abdominal pain or dyspepsia, constipation, and weight loss. In total, 187 (44\%) patients had upper GI symptoms (abdominal pain, dyspepsia/ indigestion, nausea and Vomiting, hematemesis, etc) and 33 (8\%) patients had lower GI symptoms. Based on symptoms (upper vs lower symptoms), patients with occult bleeding are scheduled for EGD vs colonoscopy. If patients did not have any symptoms, bidirectional endoscopy was done. We could not divide into 2 groups, symptomatic and asymptomatic patients, because several asymptomatic patients had a history of GI bleeding and some symptoms in the past. Colonoscopy was done for patients with lower GI symptoms (hematochezia, melena, abdominal pain, etc) or positive fecal occult blood test. Esophagogastroduodenoscopy was done for patients with upper GI symptoms. Asymptomatic patients with IDA except celiac patients underwent bidirectional endoscopy. The study was approved by Howard University Institutional Review Board.

\section{Statistical analysis}

Association of GI lesions in patients with IDA with sex and age groups were assessed by the Fisher exact test. We also built logistic regression models to predict the GI lesion in patients with IDA if applicable. All analyses were performed by Stata 13.0 (StataCorp, College Station, TX, USA).

\section{Results}

The median (interquartile range) age was 58 (48-71) years with $50 \%$ female patients in the study group. Gross GI bleeding was observed in 189 patients (45\%), whereas 233 patients (55\%) had occult GI bleeding. In the overall analyzed group, the most frequent diagnoses based on endoscopy and histopathology were gastritis (40\%), benign colonic lesions (13\%), esophagitis (9\%), gastric ulcer (6\%), and duodenitis (6\%). There were 3 cases with stomach cancers, 2 with esophageal cancers, and 15 with colorectal cancers. Except for GI bleeding, which was significantly more frequent in men $(P=.001)$, the frequency of other lesions was not significantly different between the 2 sexes (Table 1 ).

Among all patients with IDA, 289 (71\% were 50 years or older, including $77 \%$ of men and $65 \%$ women $(P=.006)$. In patients $\geqslant 50$ years old, the frequency of GI bleeding, colon benign, and colon malignant tumor was significantly higher, whereas the frequency of colitis was significantly lower compared with younger age group (Table 2). Our study was done in African Americans, and in our study, we had just 2 cases of celiac disease that were excluded. Helicobacter pylori test was positive in 17 (4\%) patients.

In a multivariate analysis, older age (odds ratio $[\mathrm{OR}]=2.1$, $95 \%$ confidence interval $[\mathrm{CI}]: 1.3-3.2)$ and male sex $(\mathrm{OR}=1.5$, 95\% CI: 1.1-2.2) were associated with a higher rate of GI bleeding diagnosis. Our study was done in African Americans, and in our study, we had just 2 cases of celiac disease that were excluded. Helicobacter pylori test was positive in $17(0.04 \%)$ patients. Helicobacter pylori was tested in patients with dyspepsia and upper GI symptoms. These patients had gastritis on endoscopy. Thirteen patients $(0.03 \%)$ with positive $H$ pylori had gastritis without gross bleeding and rest of them had gross upper GI bleeding.

\section{Discussion}

Many patients with undetermined causes of IDA and lacking any GI disease symptoms pose a challenge for their treatment, as long as the IDA-causing disorder is not elucidated. In this study, we found that gastritis and colonic lesions are the most common GI lesions found among African Americans evaluated for IDA. Some sex-related and age-related differences were observed. Most of the studies are done in other population and ethnicity, and we did not find another study regarding IDA and GI lesion in African American population. Benign and malignant colonic lesions were significantly more present among older patients, and colitis was more prevalent in younger patients. Duodenal benign tumors were significantly more represented among women, whereas colon malignancy was more prevalent among men.

Occult GI bleeding was found in 55\% of patients. The frequency of gastritis and esophagitis without gross GI bleeding was more than gastric ulcer and duodenal ulcer. In our study, $H$ pylori test was positive in 17 (4\%) patients. Because H pyloriassociated gastritis and autoimmune atrophic gastritis can cause malabsorption, so more investigation of causes and studies are required to evaluate occult GI bleeding in the context of GI disorders.

The prevalence of benign and malignant colorectal tumors (13\% and 3\%, respectively) was similar to other published studies in other ethnicity. ${ }^{10}$ Furthermore, the frequency of 
Table 1. Distribution of different GI lesions in IDA by sex.

\begin{tabular}{|c|c|c|c|}
\hline GI LESIONS & FEMALE, N=213 (\%) & MALE, $N=209(\%)$ & $P$ VALUE \\
\hline Gross GI bleeding, No. (\%) & $83(39)$ & $106(51)$ & .001 \\
\hline Esophagitis, No. (\%) & $16(8)$ & $23(11)$ & .2 \\
\hline GU, No. (\%) & $14(7)$ & $11(5)$ & .5 \\
\hline DU, No. (\%) & $4(2)$ & $4(2)$ & .9 \\
\hline Gastritis, No. (\%) & $95(45)$ & $76(36)$ & .08 \\
\hline Duodenitis, No. (\%) & $10(5)$ & $17(8)$ & .1 \\
\hline Colitis, No. (\%) & $8(4)$ & $11(5)$ & .4 \\
\hline Esophageal benign tumor, No. (\%) & 0 & $1(0.5)$ & .5 \\
\hline Stomach benign tumor, No. (\%) & $5(2)$ & $4(2)$ & .7 \\
\hline Duodenum benign tumor, No. (\%) & $8(4)$ & $2(1)$ & .1 \\
\hline Colon benign tumor, No. (\%) & $24(11)$ & $30(14)$ & .3 \\
\hline Esophageal malignant tumor, No. (\%) & 0 & $2(1)$ & .2 \\
\hline Stomach malignant tumor, No. (\%) & $1(0.5)$ & $2(1)$ & .5 \\
\hline Colon malignant tumor & $5(2)$ & $10(5)$ & .2 \\
\hline Both-sided colon malignant tumor & $3(1)$ & 0 & .2 \\
\hline Right-sided colon malignant tumor & $1(0.5)$ & $4(2)$ & .1 \\
\hline Left-sided colon malignant tumor & $1(0.5)$ & $6(3)$ & .07 \\
\hline
\end{tabular}

Abbreviations: DU, duodenal ulcer; GI, gastrointestinal; GU, gastric ulcer; IDA, iron deficiency anemia.

Table 2. Distribution of different GI lesions in IDA by age.

\begin{tabular}{|c|c|c|c|}
\hline GI LESIONS & $<50 Y, N=123$ & $\geqslant 50 Y, N=299$ & $P$ VALUE \\
\hline Gl bleeding & $39(32)$ & $150(50)$ & .001 \\
\hline Esophagitis & $12(10)$ & $27(9)$ & .8 \\
\hline GU & $5(4)$ & $20(7)$ & .3 \\
\hline DU & 0 & $8(3)$ & .1 \\
\hline Gastritis & $55(45)$ & $116(39)$ & .2 \\
\hline Duodenitis & $9(7)$ & $18(6)$ & .6 \\
\hline Colitis & $13(11)$ & $6(2)$ & $<.001$ \\
\hline Esophageal benign tumor & 0 & $1(0.3)$ & .5 \\
\hline Stomach benign tumor & $2(2)$ & $7(2)$ & .6 \\
\hline Duodenum benign tumor & $1(1)$ & $9(3)$ & .3 \\
\hline Colon benign tumor & $7(6)$ & $47(16)$ & .005 \\
\hline Esophageal malignant tumor & 0 & $2(1)$ & .4 \\
\hline Stomach malignant tumor & $1(1)$ & $2(1)$ & .8 \\
\hline Colon malignant tumor & 0 & $15(5)$ & .008 \\
\hline Both-sided colon malignant tumor & 0 & $5(2)$ & 6 \\
\hline Right-sided colon malignant tumor & 0 & $5(2)$ & .3 \\
\hline Left-sided colon malignant tumor & 0 & $7(2)$ & .1 \\
\hline
\end{tabular}

Abbreviations: DU, duodenal ulcer; GI, gastrointestinal; GU, gastric ulcer; IDA, iron deficiency anemia. 
inflammatory GI lesions such as gastritis and esophagitis was more prevalent than GI ulcers and tumor lesions. In addition, GI lesions as a source of IDA were more frequently located in the upper GI tract than in the colon, a finding in agreement with previously reported studies. ${ }^{13-17}$

Although the leading cause of IDA in men older than 50 years and postmenopausal women is chronic GI bleeding of GI lesions; the evaluation of the GI tract in younger men should also be considered seriously. ${ }^{18,19}$ In our study, among young men with IDA, gastritis and colitis are the leading findings and there is a paucity of data in the literature regarding the cause of IDA among young men. Our study suggests that inflammatory processes may contribute to IDA in younger patients. ${ }^{20}$ In contrast, elderly patients in our study revealed a prevalence of malignancies' association with IDA. Indeed, a high rate of colon malignancies, predominantly right-sided colon carcinoma in postmenopausal women and older men with asymptomatic IDA has been reported. ${ }^{21}$ Our results also show that the benign and malignant colon cancers can be one of the important causes of IDA and this is consistent with other studies. ${ }^{22}$

In our study, we found gastritis and colitis more associated with IDA in younger patients, and our recommendation was considering upper GI endoscopy if colonoscopy is normal in the evaluation of IDA especially in younger patients. In our study, gastritis was more than peptic ulcer. Celiac disease was rare in our African American population. Comparing with other population, we had just 2 cases of celiac disease $(0.004 \%)$ that was less than the average celiac disease prevalence in other populations. So, in most of the patients, source of IDA was detected by upper and lower GI endoscopy.

\section{Conclusions}

This exploratory analysis of IDA-associated GI lesions revealed that gastritis and colonic lesions are most common lesions found among African Americans with IDA with minimal age and sex differences. Colitis was found more in younger patients, whereas IDA was more associated with lower GI malignancies in older patients. So, bidirectional endoscopy is required for unrevealing of the cause of IDA in asymptomatic patients.

\section{Author Contributions}

AS: Design of the work, data collection, drafting the article. $\mathrm{MN}$ : Data analysis and interpretation. HB: Critical revision of the article. AL: Critical revision of the article, final approval of the version to be published. AA, TH: Data collection. HA: Data analysis and interpretation, critical revision of the article, final approval of the version to be published, drafting the article.

\section{REFERENCES}

1. Endres HG, Wedding U, Pittrow D, Thiem U, Trampisch HJ, Diehm C. Prevalence of anemia in elderly patients in primary care: impact on 5-year mortality risk and differences between men and women. Curr Med Res Opin. 2009;25:1143-1158.

2. Khadem G, Scott IA, Klein K. Evaluation of iron deficiency anaemia in tertiary hospital settings: room for improvement? Intern Med J. 2012;42:658-664.

3. Kepczyk T, Kadakia SC. Prospective evaluation of gastrointestinal tract in patients with iron-deficiency anemia. Dig Dis Sci. 1995;40:1283-1289.

4. Cook IJ, Pavli P, Riley JW, Goulston KJ, Dent OF. Gastrointestinal investigation of iron deficiency anaemia. Br Med J (Clin Res Ed). 1986;292:1380-1382.

5. Goddard AF, James MW, McIntyre AS, Scott BB. Guidelines for the management of iron deficiency anaemia. Gut. 2011;60:1309-1316.

6. McIntyre AS, Long RG. Prospective survey of investigations in outpatients referred with iron deficiency anaemia. Gut. 1993;34:1102-1107.

7. Calvey HD, Castleden CM. Gastrointestinal investigations for anaemia in the elderly: a prospective study. Age Ageing. 1987;16:399-404.

8. Sayer JM, Long RG. A perspective on iron deficiency anaemia. Gut. 1993;34:1297-1299.

9. Napal JJ, Hernandez JL, Alonso J, Casuso E. [Differential factors of tumor etiology for iron deficiency anemia of probable gastrointestinal origin]. Rev Clin Esp. 2009;209:265-269.

10. Nahon S, Lahmek P, Lesgourgues B, et al. Predictive factors of GI lesions in 241 women with iron deficiency anemia. Am J Gastroenterol. 2002;97:590-593.

11. Goddard AF, McIntyre AS, Scott BB. Guidelines for the management of iron deficiency anaemia. British Society of Gastroenterology. Gut. 2000;46: IV1-IV5.

12. Carter D, Levi G, Tzur D, Novis B, Avidan B. Prevalence and predictive factors for gastrointestinal pathology in young men evaluated for iron deficiency anemia. Dig Dis Sci. 2013;58:1299-1305.

13. Reyes Lopez A, Gomez Camacho F, Galvez Calderon C, Mino Fugarolas G. Iron-deficiency anemia due to chronic gastrointestinal bleeding. Rev Esp Enferm Dig. 1999;91:345-358.

14. St John DJ, Young GP, Alexeyeff MA, et al. Evaluation of new occult blood tests for detection of colorectal neoplasia. Gastroenterology. 1993;104:1661-1668.

15. Allison JE, Tekawa IS, Ransom LJ, Adrain AL. A comparison of fecal occult-blood tests for colorectal-cancer screening. N Engl J Med. 1996;334: 155-159.

16. Allison JE, Feldman R, Tekawa IS. Hemoccult screening in detecting colorectal neoplasm: sensitivity, specificity, and predictive value. Long-term follow-up in a large group practice setting. Ann Intern Med. 1990;112:328-333.

17. Rockey DC, Koch J, Cello JP, Sanders LL, McQuaid K. Relative frequency of upper gastrointestinal and colonic lesions in patients with positive fecal occultblood tests. N EnglJ Med. 1998;339:153-159.

18. Rockey DC. Occult gastrointestinal bleeding. N Engl J Med. 1999;341:38-46.

19. Andrews NC. Disorders of iron metabolism. N Engl J Med. 1999;341: 1986-1995.

20. Danese S, Hoffman C, Vel S, et al. Anaemia from a patient perspective in inflammatory bowel disease: results from the European Federation of Crohn's and Ulcerative Colitis Association's online survey. Eur J Gastroenterol Hepatol. 2014;26:1385-1391.

21. Niv E, Elis A, Zissin R, Naftali T, Novis B, Lishner M. Iron deficiency anemia in patients without gastrointestinal symptoms-a prospective study. Fam Pract. 2005;22:58-61.

22. Pengelly S, Fabricius M, McMenamin D, et al. Attendance at iron deficiency anaemia clinic: audit of outcomes 5 years on. Colorectal Dis. 2013;15:423-427. 